\title{
SUMO and ubiquitin in the nucleus: different functions, similar mechanisms?
}

\author{
Grace Gill ${ }^{1}$ \\ Department of Pathology, Harvard Medical School, Boston, Massachusetts 02115, USA
}

\begin{abstract}
The small ubiquitin-related modifier SUMO posttranslationally modifies many proteins with roles in diverse processes including regulation of transcription, chromatin structure, and DNA repair. Similar to nonproteolytic roles of ubiquitin, SUMO modification regulates protein localization and activity. Some proteins can be modified by SUMO and ubiquitin, but with distinct functional consequences. It is possible that the effects of ubiquitination and SUMOylation are both largely due to binding of proteins bearing specific interaction domains. Both modifications are reversible, and in some cases dynamic cycles of modification may be required for activity. Studies of SUMO and ubiquitin in the nucleus are yielding new insights into regulation of gene expression, genome maintenance, and signal transduction.
\end{abstract}

Reversible posttranslational modifications are widely used to dynamically regulate protein activity. Proteins can be modified by small chemical groups, sugars, lipids, and even by covalent attachment of other polypeptides. The most well-known example of a polypeptide modifier is ubiquitin. Posttranslational modification by ubiquitin plays a central role in targeting proteins for proteolytic degradation by the proteasome, although covalent attachment of ubiquitin to proteins can also regulate localization and/or activity independent of proteolysis. In addition to ubiquitin, there are several ubiquitin-like proteins (UbLs) that can also be conjugated to, and alter the function of, substrate proteins. One Ubl in particular, the small ubiquitin-related modifier (SUMO) has been shown to covalently modify a large number of proteins with important roles in many cellular processes including gene expression, chromatin structure, signal transduction, and maintenance of the genome. The enzymatic machinery that adds and removes SUMO is similar to, but distinct from, the ubiquitination machinery. Posttranslational modification by SUMO has not been generally associated with increased protein degradation. Rather, similar to nonproteolytic roles of ubiqui-

[Keywords: SUMO; ubiquitin; transcription; DNA repair; chromatin; nucleus]

${ }^{1}$ Correspondence.

E-MAIL grace_gill@hms.harvard.edu; FAX (617) 432-6225.

Article and publication are at http://www.genesdev.org/cgi/doi/10.1101/ $\operatorname{gad} .1214604$. tin, SUMO modification regulates protein localization and activity.

This review focuses on recent advances in our understanding of SUMO function and regulation, drawing on a limited set of examples relating to gene expression, chromatin structure, and DNA repair. Comparison of SUMO and ubiquitin activities in the nucleus reveals interesting differences in function and suggests surprising similarities in mechanism. Thus, for example, modification of transcription factors and histones by ubiquitin is generally associated with increased gene expression whereas modification of transcription factors and histones by SUMO is generally associated with decreased gene expression. In some cases, SUMO and ubiquitin may directly compete for modification of target lysines. Despite the different functional consequences associated with these modifications, current data supports the hypothesis that SUMO, like ubiquitin, largely functions to promote interactions with proteins that have little or no affinity for the unmodified substrate. Both SUMOylation and ubiquitination are reversible, and, in some cases, dynamic cycles of conjugation/deconjugation may be required for regulated activity. Advances in understanding the nonproteolytic roles of SUMO and ubiquitin in the nucleus are yielding new insights into regulation of fundamental cellular processes.

\section{SUMO is structurally related to ubiquitin}

Compared to posttranslational modifiers such as a phosphate or acetyl group, ubiquitin and ubiquitin-related proteins are structurally complex. Specific surface residues of ubiquitin participate in different ubiquitindependent interactions such as binding to the proteasome or components of the endocytic machinery (SloperMould et al. 2001). NMR studies have shown that SUMO-1, which is $18 \%$ identical to ubiquitin, has a similar protein fold (Fig. 1; Bayer et al. 1998). Importantly, despite the similar protein fold, the distribution of charged residues on the surface of SUMO is very different from that of ubiquitin or other UbLs. In addition, SUMO has an Nterminal extension not found in ubiquitin. These differences likely account for the finding that distinct enzymes mediate SUMO conjugation and deconjugation as well as the unique activities attributed to SUMO. 


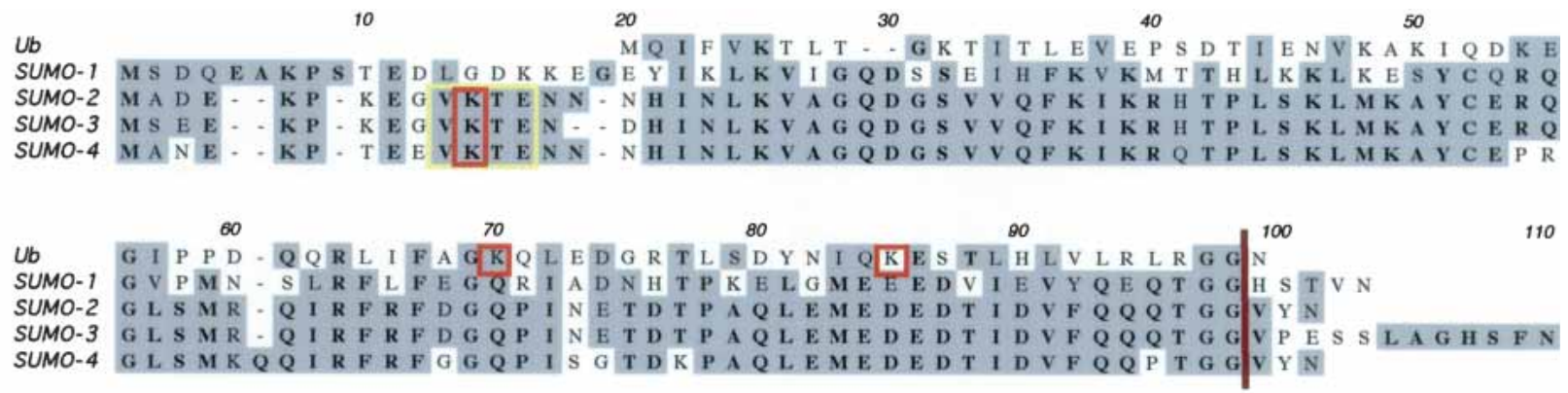

B

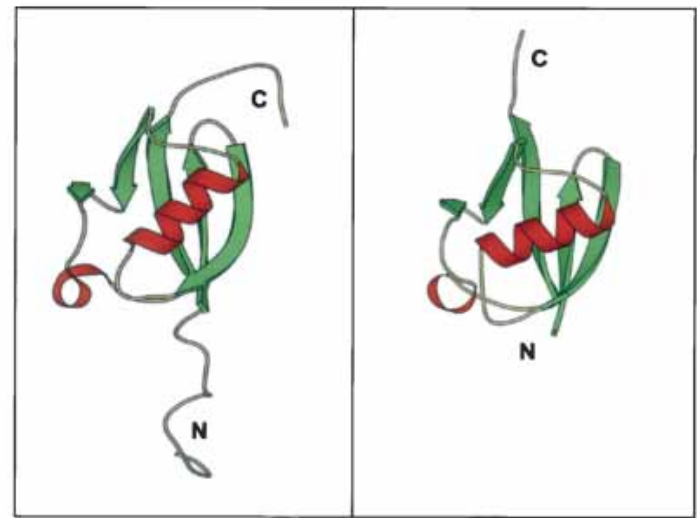

SUMO-1

Ubiquitin

Figure 1. SUMO is highly related to ubiquitin. $(A)$ Amino acid sequence alignments of ubiquitin and the four SUMO homologs from human. Identities are indicated in bold and similarities are shaded. A consensus motif for SUMOylation present in SUMO-2, SUMO-3, and SUMO-4 is boxed in yellow; the SUMO acceptor lysine $(\mathrm{K})$ in this motif is boxed in red. Ubiquitin Lys 48 and Lys 63 , which serve as common sites for ubiquitin polymerization, are boxed in red. The site of cleavage to produce the mature proteins with C-terminal glycine-glycine residues is also indicated. A polymorphism at position 55 in SUMO-4 (M55V) has been described in the human population (Bohren et al. 2004). (B) Ribbon diagrams highlight the similarity of the three-dimensional structures of SUMO-1 and ubiquitin (Bayer et al. 1998). Secondary structure elements are indicated: $\beta$ sheets are green and $\alpha$ helices are red. Notably, SUMO has an N-terminal extension not found in ubiquitin. Adapted with permission from a drawing by Peter Bayer (Bayer et al. 1998; () 1998 Journal of Molecular Biology).

Four SUMO homologs have been described in mammals. SUMO-1 and SUMO-2/3 appear to modify both common and different substrates. Thus, some substrates may be simultaneously modified by SUMO-1 and SUMO-2 whereas RanGAP1, for example, is predominately modified by SUMO-1 and Topoisomerase II is predominantly modified by SUMO-2/3 (Saitoh and Hinchey 2000; Azuma et al. 2003; Vertegaal et al. 2004; Zhao et al. 2004). The recently described SUMO-4 has a restricted pattern of expression with highest levels reported in the kidney (Bohren et al. 2004). Currently, the mechanisms that determine selective modification by specific SUMO isoforms are not known, and the functional significance of modification by specific SUMO isoforms also remains to be determined.

The ability of ubiquitin to form polymeric chains, where two or more ubiquitins are covalently attached to one another, is critical for many biological activities of ubiquitin. Polymeric ubiquitin is structurally and functionally diverse because multiple lysines in Ub can each serve as a site of ubiquitin attachment. The well-known ability of ubiquitin to interact with the proteasome, for example, is largely a property of Lys 48 -linked ubiquitin chains at least four subunits long. In contrast, SUMO is generally thought to function as a monomer. SUMO-1, SUMO-2 and SUMO-3, have been observed to form polymeric chains in vitro; however, the functional significance, if any, of SUMO chains in vivo has not been established (Johnson and Gupta 2001; Tatham et al. 2001; Pichler et al. 2002). Monomeric SUMO provides all essential functions in yeast, as a mutant form of yeast SUMO lacking the major SUMO acceptor lysines is able to support yeast viability (Bylebyl et al. 2003). Interestingly, a mutant form of SUMO-2 lacking the major site of SUMOylation differs from wild-type SUMO-2 in its ability to influence production of Amyloid $\beta$ peptide when overexpressed (Li et al. 2003). Thus, it remains possible that polymerization or other posttranslational modifications of SUMO may add complexity to SUMO function in mammalian cells.

\section{The SUMOylation machinery}

There are striking similarities between the machinery that attaches SUMO to substrate proteins and the enzymes that participate in ubiquitination (Fig. 2; Pickart 


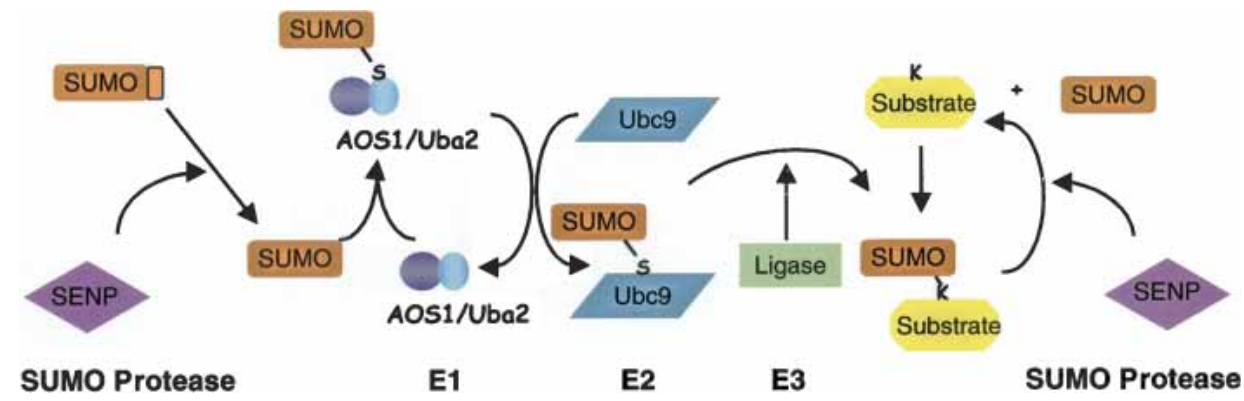

Figure 2. The SUMO conjugation pathway. The SUMO precursor is cleaved by SUMO-specific proteases (SENPs) with C-terminal hydrolase activity to expose a C-terminal glycine-glycine. In an ATP-dependent reaction, mature SUMO forms a thioester conjugate with the heterodimeric SUMO E1 activating enzyme Aos1/Uba2. SUMO is then transferred to the SUMO E2 conjugating enzyme Ubc9, with which it also forms a thioester intermediate. From Ubc9, SUMO is conjugated to a substrate protein via an isopeptide bond with a lysine residue (K). Several unrelated SUMO E3 ligases have been shown to stimulate transfer of SUMO from Ubc9 to specific substrates. SUMO E3 ligases may function as single polypeptides or as multiprotein complexes (see text). SUMO modification is reversible and SUMO is removed from substrates by SUMO-specific proteases (SENPs) with isopeptidase activity.

2001; K.I. Kim et al. 2002). Ubiquitin and SUMO are each covalently attached to substrate proteins via an isopeptide bond between a C-terminal glycine in the UbL and a lysine residue in the substrate. The E1 activating and E2 conjugating enzymes involved in SUMOylation are highly related to the E1 and E2 enzymes that participate in ubiquitination. In contrast to the ubiquitin system where dozens of E2 enzymes have been identified, Ubc9 is the only known SUMO E2 conjugating enzyme. A consensus SUMO acceptor site has been identified consisting of the sequence $\Psi \mathrm{KXE}$, where $\Psi$ is a large hydrophobic amino acid and $\mathrm{K}$ is the site of SUMO conjugation (Rodriguez et al. 2001). Consistent with structural studies showing direct recognition of this consensus motif by the Ubc9 active site, recombinant E1, E2, and SUMO are sufficient for ATP-dependent SUMO modification of substrates in vitro (Bernier-Villamor et al. 2002).

In the ubiquitin system, specificity and efficiency of ubiquitin transfer to substrates is dependent on the activity of a class of proteins termed ubiquitin E3 ligases (Pickart 2001). Ubiquitin E3s of the HECT domain family transfer ubiquitin from the E2 to a cysteine in the HECT domain as an intermediate to transfer to a substrate lysine. The majority of ubiquitin E3 ligases, however, including a large family of proteins containing a RING domain, are thought to function not as enzymes but as adaptors. These ubiquitin E3 ligases interact with both the E2 and the substrate, bringing the two together and thereby increasing the efficiency of ubiquitin transfer. Although some ubiquitin E3s function as single polypetides, many, such as the anaphase promoting complex (APC) and E3s of the SCF family, are surprisingly large multiprotein complexes with distinct subunits that mediate binding to the $\mathrm{E} 2$ and the substrate.

Several SUMO E3 ligases have been identified that promote transfer of SUMO from the E2 to specific substrates. Although not required for SUMOylation in vitro, SUMO E3 ligases may be important in regulating substrate selection in vivo, particularly for substrates that lack consensus SUMO acceptor motifs. To date, three unrelated proteins have been suggested to have SUMO
E3 ligase activity: RanBP2, the PIAS proteins, and the polycomb group protein Pc2. Although these are termed "ligases", these SUMO E3s most likely function as adaptors. RanBP2 and the PIAS proteins interact with the SUMO E2 conjugating enzyme Ubc9 and promote transfer of SUMO from Ubc9 to substrate proteins (Johnson and Gupta 2001; Kahyo et al. 2001; Takahashi et al. 2001; Pichler et al. 2002). The E3 activity of RanBP2 is specific: RanBP2 stimulates SUMO modification of some substrates such as RanGAP1 and Sp100 but not others such as p53 (Pichler et al. 2002). Notably, the different SUMO E3 ligases identified to date have distinct subcellular localizations: RanBP2 is associated with the nuclear pore complex, the PIAS proteins are found in the nucleoplasm and nuclear bodies, and Pc2 is found in a subnuclear structure called a Polycomb body (Sachdev et al. 2001; Kotaja et al. 2002; Pichler et al. 2002; Kagey et al. 2003). Localization of the SUMO E3 ligases is likely to contribute to functional specificity in vivo.

The PIAS proteins were initially described as protein inhibitors of activated STATs and subsequent studies have shown that the PIAS proteins influence the activity of many transcription factors (Chung et al. 1997; Liu et al. 1998; Kotaja et al. 2000; Gross et al. 2001). Similar to a large class of E3 ubiquitin ligases, the PIAS proteins contain a RING finger motif that is required for their SUMO E3 ligase activity (Kahyo et al. 2001; Sachdev et al. 2001). Studies of PIAS proteins bearing mutations in the RING domain suggest that the PIAS proteins have both E3 SUMO ligase-dependent and -independent activities (Sachdev et al. 2001; Megidish et al. 2002; Gross et al. 2004).

Given the widespread use of large multiprotein E3s in the ubiquitin system, it is tempting to speculate that multiprotein E3s may be important for substrate selection in the SUMO pathway as well. Recent studies of the polycomb group protein $\mathrm{Pc} 2$ are consistent with the proposal that Pc2 may be a component of a multiprotein SUMO E3 ligase (Kagey et al. 2003). Polycomb group proteins form multiprotein complexes that repress gene 
expression through alterations of chromatin structure. Although recombinant E1, E2, and SUMO are sufficient for SUMOylation of the transcriptional corepressor CtBP-1 in vitro, expression of Pc2 increased SUMO modification of CtBP-1 in vivo (Kagey et al. 2003). Transfected Pc2 was shown to colocalize Ubc9, SUMO, and CtBP-1 in a subnuclear structure called a polycomb group (PcG) body. The stimulatory effect of Pc2 in in vitro SUMOylation reactions was modest and direct interactions between Pc2 and the E2 Ubc9 have not been reported. These data are most consistent with a model in which Pc2 functions as part of a multiprotein SUMO E3 complex, although other models are possible. Multiprotein SUMO E3 ligases present a challenge to characterization, as individual subunits are not expected to have full E3 activity and definitive proof may await demonstration that the complex has SUMO E3 ligase activity in vitro. It is likely that additional SUMO E3 ligase activities, including multiprotein E3 complexes, await discovery.

Modification of proteins by ubiquitin and SUMO is dynamic and reversible. SUMO-specific proteases participate in both processing of immature SUMO and removal of SUMO conjugates from substrates (Fig. 2). Both SUMO conjugation and deconjugation have been shown to be required for cell cycle progression in yeast. Thus, one of the two SUMO proteases in yeast, Ulp1, is essential for cell proliferation, and expression of a processed form of SUMO does not complement loss of Ulp1 (Li and Hochstrasser 1999; Taylor et al. 2002). To date, four mammalian homologs of Ulp1, SENP1, SENP2, SENP3, and SENP6, have been shown to have SUMO-specific protease activity (Gong et al. 2000; Kim et al. 2000;
Nishida et al. 2000, 2001). Although both the known SUMO-specific proteases and the ubiquitin-specific proteases are cysteine proteases, these enzymes share no sequence similarity. The mammalian SUMO proteases have been found to have distinct subcellular localizations: SENP1 has been localized to the nucleoplasm and nuclear bodies, SENP2 has been found at the nuclear pore, SENP3 localized to the nucleolus, and SENP6 was cytoplasmic (Gong et al. 2000; Kim et al. 2000; Nishida et al. 2000; Bailey and O'Hare 2002; Hang and Dasso 2002). Studies in both yeast and mammalian systems suggest that subcellular localization contributes to substrate selection by the SUMO proteases in vivo /Gong et al. 2000; Hang and Dasso 2002; Li and Hochstrasser 2003). Undoubtedly, future studies will reveal more about the functional specificity of the different SUMO proteases in mammals.

\section{Functions of SUMO}

Since the identification of the first SUMO-modified protein, RanGAP, in 1996 (Matunis et al. 1996), a large number of proteins have been shown to be posttranslationally modified by SUMO and new substrates of SUMO-modification continue to be identified at a rapid pace. Many of the known targets of SUMOylation are nuclear proteins with important roles in regulating transcription, chromatin structure, and DNA repair. Furthermore, the nuclear targets of many signaling pathways including TGF $\beta$, wnt, and cytokines are posttranslationally modified by SUMO. Some of the many proteins now known to be modified by SUMO are shown in Figure 3. It is interesting to note that some of these same proteins are

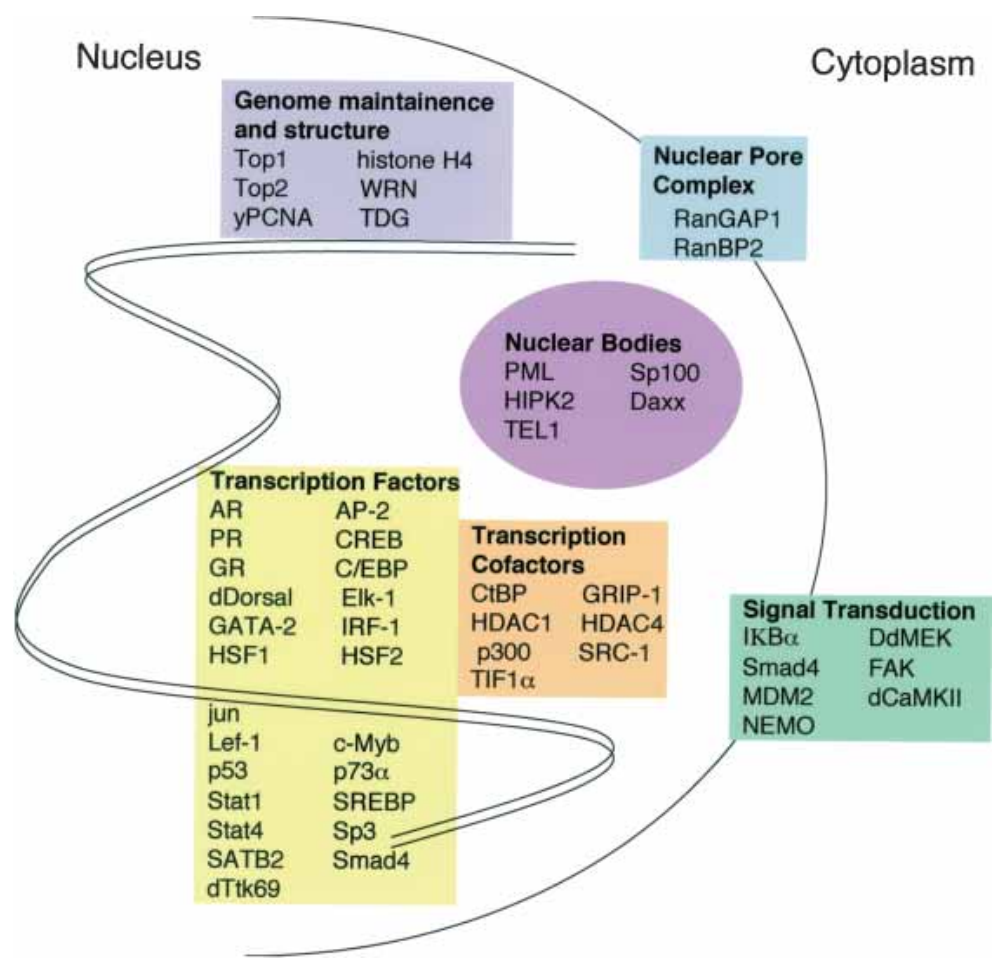

Figure 3. Some SUMO-modified proteins. Some of the many proteins that have been found to be posttranslationally modified by SUMO are listed and grouped by function/localization. Many SUMOmodified proteins function in regulation of transcription, chromatin structure, maintenance of the genome, and signal transduction. All proteins are of mammalian origin unless specifically indicated. $(\mathrm{y})$ Yeast; (d) Drosophila; (Dd) Dictyostelium. See main text and Seeler and Dejean (2003) for references. Adapted with permission from Seeler and Dejean (2003; (C) 2003 Nature Reviews Molecular Cell Biology; http://www.nature.com/nrm). 
also posttranslationally modified by ubiquitin, often with different consequences (Table 1). In some cases, SUMO modification has been shown to compete with ubiquitination or acetylation for common lysine residues. In most cases SUMO modification is likely to regulate protein-protein interactions. Although much remains to be learned about the mechanisms by which SUMO modification alters substrate protein activity, it is clear that posttranslational modification by SUMO regulates activity and/or localization of proteins with important roles in cell proliferation, differentiation, and apoptosis.

\section{SUMO regulates nuclear and subnuclear localization}

Posttranslational modification by SUMO has been shown to regulate subcellular localization of many targets including RanGAP, the first identified SUMO substrate (Matunis et al. 1996). RanGAP is a small GTPaseactivating protein that plays a role in nuclear import. Unmodified RanGAP is cytoplasmic, whereas SUMOmodified RanGAP is associated with the nuclear pore (Matunis et al. 1996; Mahajan et al. 1997). SUMO modification of RanGAP greatly increases its interaction with RanBP2 (also known as Nup358), a component of the nuclear pore complex and a SUMO E3 ligase (Pichler et al. 2002). Increased binding of SUMO-modified RanGAP to RanBP2 requires both SUMO conjugation and regions of RanGAP outside the SUMO acceptor site (Matunis et al. 1998). This finding suggests that SUMO-modified RanGAP presents a unique protein interaction surface due to either presentation of elements from both RanGAP and SUMO or a structural rearrangement of RanGAP induced by the modification. Although the
RanGAP homolog in budding yeast is not SUMOylated, the SUMO conjugation pathway has also been shown to play a role in nuclear trafficking in this organism (Stade et al. 2002). In mammalian cells, SUMO modification of several substrates has been linked to nuclear import. In the case of the IKB kinase regulator NEMO, for example, fusion of NEMO to SUMO was sufficient for localization to the nucleus (Huang et al. 2003). Localization of the RanBP2 SUMO E3 ligase at the nuclear pore may contribute to a broad role for SUMO in regulation of nuclear trafficking (for review, see Melchior et al. 2003).

Another well-characterized example of SUMO-dependent changes in subcellular localization comes from studies of the tumor suppressor PML. PML was originally identified as part of a fusion protein with RAR $\alpha$ resulting from a chromosomal translocation associated with acute promyelocytic leukemia. Wild-type PML, which is posttranslationally modified by SUMO, is present in a subnuclear structure called the PML nuclear body. Many other SUMO-modified proteins including transcription factors, chromatin modifiers, and proteins involved in genomic maintenance have also been found in PML nuclear bodies (Zhong et al. 2000b). Notably, both SUMO E3 ligases and SUMO-specific proteases have also been found to localize in PML nuclear bodies (Sachdev et al. 2001; Best et al. 2002; Kotaja et al. 2002). Mutation of the SUMO acceptor lysines in PML or overexpression of a SUMO protease causes nuclear body components such as CBP or Sp100 to relocalize in the nucleus (Zhong et al. 2000a; Best et al. 2002). These findings suggest that SUMO-modified PML supports some protein-protein interactions important for assembly or stability of this subnuclear domain. Although the function of the PML nuclear body remains a subject of active investigation, disruption of PML nuclear bodies is asso-

Table 1. Examples of proteins modified by SUMO and ubiquitin with different consequences

\begin{tabular}{|c|c|c|c|c|}
\hline Protein & Function & Role of SUMOylation & Role of ubiquitination & $\begin{array}{l}\text { Common } \\
\text { lysine? }\end{array}$ \\
\hline $\mathrm{IKB} \alpha$ & $\begin{array}{l}\text { Signal transduction/ } \\
\text { Inhibition of NFKB }\end{array}$ & $\begin{array}{l}\text { Stabilizes IKB } \alpha \text { by competition with } \\
\text { ubiquitin }\end{array}$ & $\begin{array}{l}\text { Promotes proteasome-mediated } \\
\text { degradation }\end{array}$ & yes \\
\hline NEMO & $\begin{array}{l}\text { Signal transduction/ } \\
\text { IKK regulation }\end{array}$ & Promotes nuclear localization & Required for IKK activation & \\
\hline yPCNA & $\begin{array}{l}\text { DNA replication and } \\
\text { repair }\end{array}$ & Regulates DNA repair during replication & $\begin{array}{l}\text { Monoubiquitination promotes } \\
\text { translesion DNA repair; } \\
\text { polyubiquitination promotes } \\
\text { error-free DNA repair }\end{array}$ & yes \\
\hline PML & Tumor supressor & $\begin{array}{l}\text { Regulates subnuclear localization; required } \\
\text { for integrity of nuclear bodies }\end{array}$ & $\begin{array}{l}\text { Promotes proteasome-mediated } \\
\text { degradation }\end{array}$ & \\
\hline p53 & $\begin{array}{l}\text { Transcription factor/ } \\
\text { tumor supressor }\end{array}$ & $\begin{array}{l}\text { Variable effects observed; reduces } \\
\text { transcriptional activation in some } \\
\text { contexts }\end{array}$ & $\begin{array}{l}\text { Promotes proteasome-mediated } \\
\text { degradation }\end{array}$ & \\
\hline $\begin{array}{l}\text { Glucocorticoid } \\
\text { receptor (GR) }\end{array}$ & Transcription factor & $\begin{array}{l}\text { Reduces transcriptional activation } \\
\text { dependent on promoter context }\end{array}$ & $\begin{array}{l}\text { Promotes proteasome-mediated } \\
\text { degradation }\end{array}$ & \\
\hline $\mathrm{c}-\mathrm{Myb}$ & Transcription factor & Reduces transcriptional activation & $\begin{array}{l}\text { Promotes proteasome-mediated } \\
\text { degradation }\end{array}$ & \\
\hline HDAC-1 & $\begin{array}{l}\text { Histone deacetylase/ } \\
\text { transcriptional } \\
\text { corepressor }\end{array}$ & $\begin{array}{l}\text { Promotes deacetylase activity and } \\
\text { transcriptional repression }\end{array}$ & $\begin{array}{l}\text { Promotes proteasome-mediated } \\
\text { degradation }\end{array}$ & \\
\hline
\end{tabular}

$\overline{{ }^{a}}$ Indicates that competition by ubiquitin and SUMO for a common lysine in the substrate protein has been reported to impact activity. 
ciated with changes in cell proliferation, differentiation, and survival (Zhong et al. 2000b).

The existence of multiple SUMO isoforms in mammals may add complexity to the role of SUMO in localization. Immunostaining has revealed that SUMO- 1 and SUMO-2/3 have partially overlapping but distinct patterns of localization (Saitoh and Hinchey 2000). Attachment of SUMO-1 or SUMO-3 to the transcription factor SATB2 by gene fusion resulted in distinct patterns of subnuclear localization with SUMO-1-SATB2 localizing to nuclear dots and SUMO-3-SATB2 to the nuclear periphery (Dobreva et al. 2003). Although SUMO has properties of a cellular address label, clearly substrate protein sequences also contribute to localization, as SUMO-1modified PML and Ran-GAP have different localization patterns, and, in many cases, SUMO modification has not been observed to alter protein localization. Thus, for example, LEF1 localization in nuclear bodies correlates with binding to the SUMO E3 ligase PIASy, but does not require SUMO modification of LEF1 (Sachdev et al. 2001). In another example, although Sp100 is a SUMOmodified protein that colocalizes with PML, SUMOylation of Sp100 itself is not required for localization of this protein to the nuclear body (Sternsdorf et al. 1999).

The role of SUMO in regulating subcellular localization is very reminiscent of similar activities of monoubiquitin. Studies of the Fanconi Anemia protein FANCD2 have shown that monoubiquitin also regulates subnuclear localization (Garcia-Higuera et al. 2001). Fanconi Anemia is a cancer susceptibility disorder associated with sensitivity to DNA damage. The FANCD2 protein is monoubiquitinated in response to DNA damage. Posttranslational modification by monoubiquitin causes the FANCD2 protein to relocalize from a diffuse nuclear pattern to discrete nuclear foci. Monoubiquitinated FANCD2 colocalizes with the BRCA1 tumor suppressor. The other gene products implicated in Fanconi Anemia are required for monoubiquitinaton of FANCD2, suggesting that defects in this posttranslational modification are central to the disease.

Outside the nucleus, monoubiquitination plays an important role in endocytosis of many cell surface receptors (for review, see Schnell and Hicke 2003). In this pathway, monoubiquitin itself carries an internalization signal that is recognized by proteins that directly bind noncovalently to ubiquitin. Several ubiquitin-binding domains have been characterized including the ubiquitin-associated domain (UBA), ubiquitin interacting motif (UIM), ubiquitin E2 variant (UEV), and Cue-1 homologous (CUE; for review, see Schnell and Hicke 2003). Although little is known about the structure or function of SUMO recognition motifs, several proteins have been shown to bind noncovalently to SUMO and at least one SUMO interacting motif (SIM) has been identified (Minty et al. 2000; Ahn et al. 2001; Hardeland et al. 2002; Lin et al. 2002; Engelhardt et al. 2003; Rosendorff et al. 2004). Noncovalent binding of the PIAS SUMO E3 ligases to SUMO-modified proteins has been suggested to contribute to regulation of transcription by PIAS proteins, independent of their E3 ligase activity (Kotaja et al. 2002).
Thus it is possible that, similar to ubiquitin, many of the effects of SUMO modification on substrate proteins, including altered localization and activity, result from direct binding of conjugated SUMO by proteins containing SUMO-binding domains (Fig. 4).

\section{SUMO regulates gene expression}

Many of the SUMO-modified proteins identified to date are promoter-specific transcription factors, coactivators, or corepressors (see Fig. 3). Although the effects of SUMO modification on transcription factor activity are varied, in the majority of cases that have been described to date, attachment of SUMO appears to repress the activity of transcriptional activators (for reviews, see Gill 2003; Verger et al. 2003). The transcription factor Sp3, for example, has been shown to be SUMO modified in vivo and removal of SUMO by mutation of the Sp3 acceptor lysines or cotransfection with a SUMO protease dramatically increased transcriptional activity of Sp3 (Ross et al. 2002; Sapetschnig et al. 2002). These findings suggest that SUMO modification may contribute to the complex activity of Sp3, which has long been known to function as both an activator and a repressor of transcription dependent on context. The major site of SUMO modification in Sp3 lies within a previously defined inhibitory domain. Similarly, the sites of SUMO attachment in many transcription factors, including C/EBP proteins, Elk-1, c-Myb, and steroid hormone receptors, have also been mapped to regions previously shown to function as inhibitory domains (Poukka et al. 2000; Abdel-Hafiz et al. 2002; Bies et al. 2002; J. Kim et al. 2002; Tian et al. 2002; Subramanian et al. 2003; Yang et al. 2003). Thus, SUMO modification may function to repress activation by many transcription factors. It is curious to note that SUMO modification of transcription factors and histones (see below) has been generally suggested to repress gene expression, whereas, aside from its role in protein degradation, ubiquitin modification of transcription factors and histones has been generally associated with gene activation (Fig. 4).

SUMO modification could negatively regulate transcription factor activity through altered interactions with DNA, chromatin, or other proteins. SUMO modification has been suggested to stimulate DNA binding by HSF (Goodson et al. 2001; Hong et al. 2001). For several transcription factors, however, including LEF, Sp3, and Ttk69, SUMO modification does not alter DNA-binding activity in vitro (Lehembre et al. 2000; Sachdev et al. 2001; Sapetschnig et al. 2002). The effects of SUMO modification on association of transcription factors with DNA in vivo are largely unknown. Mutation of the SUMO acceptor lysines in SATB2 was found to stimulate binding to the endogenous immunoglobulin heavy chain gene, suggesting that SUMO modification may reduce chromatin association of this factor (Dobreva et al. 2003). Although SUMO regulates localization of many transcription factors, a "sequestration" model, whereby SUMO modification causes relocalization of the transcription factor to a subnuclear domain where it cannot 


\section{A Localization}

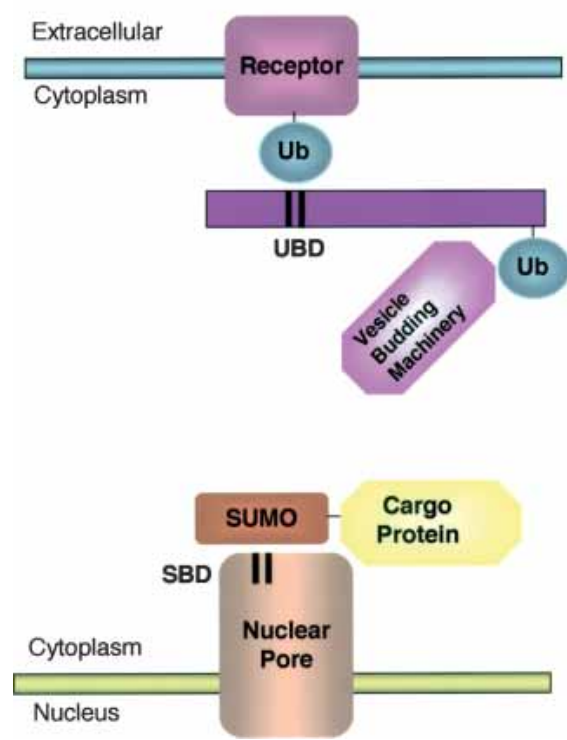

B Transcription factor activity
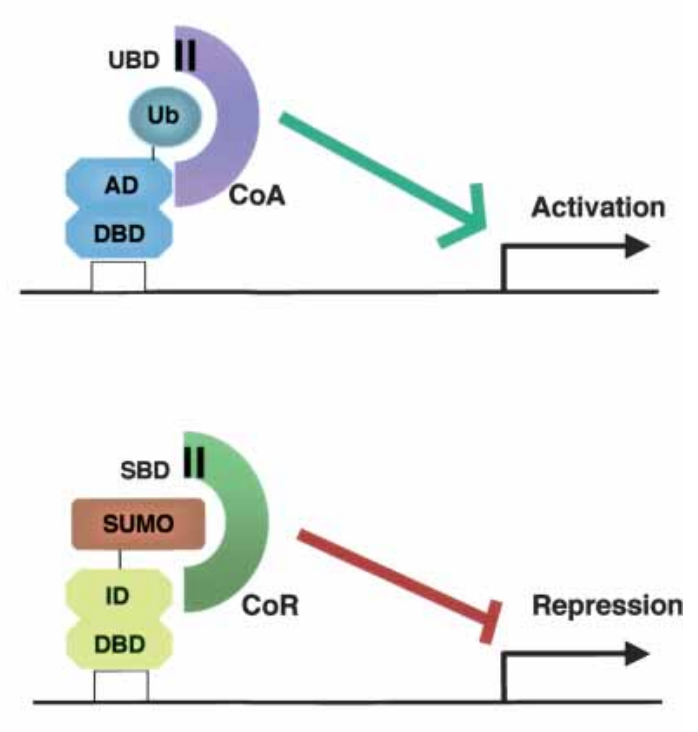

Figure 4. Ubiquitin and SUMO are proposed to regulate protein localization and activity through interactions with proteins bearing specific ubiquitin- or SUMO-binding domains. $(A)$ Model for regulation of localization by ubiquitin or SUMO. (Top) Posttranslational modification of a cell surface receptor by monoubiquitination (Ub) promotes interactions with an adaptor protein containing a ubiquitin-binding domain (UBD). This ubiquitin-dependent interaction promotes endocytosis of the receptor. In many cases, the UBD-containing adaptor protein is itself monoubiquitinated. (Bottom) SUMO modification of a cargo protein promotes interactions with a protein containing a SUMO-binding domain (SBD). In the illustration, this interaction localizes the SUMO-modified cargo to the nuclear pore; other SUMO-dependent subcellular localizations are also observed. $(B)$ Model for regulation of transcription factor activity by ubiquitin or SUMO. (Top) A transcription factor bearing a DNA-binding domain (DBD) and an activation domain (AD) is conjugated to ubiquitin (Ub). The ubiquitinated transcription factor interacts with a coactivator (CoA) bearing a ubiquitin-binding domain (UBD). Binding of the coactivator leads to increased transcription. Posttranslational modification of transcription factors by ubiquitin also promotes proteasome-dependent degradation (not shown; see Table 1). (Bottom) A transcription factor bearing a DNA-binding domain (DBD) and an inhibitory domain (ID) is shown to be modified by SUMO in the ID. According to the model, SUMO directly participates in binding to a corepressor (CoR) containing a SUMO-binding domain (SBD). SUMO-dependent binding of the corepressor may be influenced by other transcription factors bound at the same promoter, leading to context-dependent effects (not shown). Binding of the corepressor by the SUMO-modified transcription factor leads to transcriptional repression. Many SBD containing proteins may also be substrates for SUMOylation (not shown).

access the DNA template, is not likely to be generally applicable. SUMO-modified proteins are not generally excluded from chromosomal DNA, as immunostaining of Drosophila polytene chromosomes revealed SUMO association with multiple discrete loci (Lehembre et al. 2000).

Current findings support the view that, in many cases, SUMO modification inhibits transcription-factor activity by promoting interactions with proteins that repress transcription. In several contexts SUMO-dependent repression of transcription has been observed, suggesting that SUMO-modified transcription factors bound at the promoter actively participate in repression (J. Kim et al. 2002; Ross et al. 2002; Holmstrom et al. 2003; Yang et al. 2003). Furthermore, recruitment of SUMO to a promoter, in the context of a Gal4-SUMO fusion, is sufficient for repression, suggesting that SUMO itself can directly bind transcriptional (co)repressors (Ross et al. 2002; Yang et al. 2003). Consistent with this hypothesis, SUMO modification of the transcription factor Elk-1 has been shown to increase association with the histone deacetylase HDAC2 and this has been correlated with a decrease in histone acetylation at the repressed promoter (Yang and Sharrocks 2004). Similarly, SUMO-modified p300, but not unmodified p300, has been shown to bind the histone deacetylase HDAC6 (Girdwood et al. 2003). Other corepressors, in addition to the HDACs, may also be recruited to promoters dependent on SUMO (Fig. 4).

Studies of the mechanisms by which SUMO modification regulates transcription-factor activity are complicated by the fact that in many cases not only the activator but also its associated coactivators, and/or corepressors, are modified by SUMO (Fig. 3). It is possible that association of multiple SUMO-modified proteins in a complex may amplify effects of experimental alterations in the SUMOylation machinery or mask effects of mutation of individual SUMO acceptor lysines. If SUMO functions to promote interactions important for transcriptional repression, it may not matter exactly which subunit in a transcription factor complex is SUMO modified, so much as that SUMO is conjugated to one or more subunits in the complex. According to this view, it is modification of the complex per se that is important for regulation (Jackson 2001). 
An intriguing aspect of SUMO-dependent changes in transcription factor activity is the observation that SUMO may have promoter context-dependent effects. In particular, it has been suggested that SUMO modification may specifically interfere with the ability of some transcription factors to function synergistically when bound at multiple sites in a promoter (Holmstrom et al. 2003). Previous studies of the glucocorticoid receptor (GR) identified a region referred to as a synergy control (SC) motif, mutation of which led to an increase in the activity of GR from promoters bearing multiple, but not single, sites (Iniguez-Lluhi and Pearce 2000). The SC motif contains a consensus SUMO acceptor site, $\Psi \mathrm{KXE}$, and recent data have shown that this is, in fact, the major site of SUMO conjugation in GR (Le Drean et al. 2002; Tian et al. 2002). Synergy control motifs identified in several other transcription factors, such as the Androgen receptor and $\mathrm{C} / \mathrm{EBP} \alpha$, have also been shown to be sites of posttranslational modification by SUMO (Poukka et al. 2000; Subramanian et al. 2003). Strikingly, mutation of the SUMO acceptor site in GR or overexpression of SUMO-1 has been shown to increase activity from some GR target promoters but not others (Le Drean et al. 2002; Tian et al. 2002; Holmstrom et al. 2003). These findings suggest that SUMO modification of transcription factors may not function as a simple "ON/OFF" switch but may provide more subtle, context-dependent, regulatory input to modulate gene expression.

Posttranslational modification by ubiquitin is an important regulator of transcription factor activity (Conaway et al. 2002; Muratani and Tansey 2003). The most well-characterized mechanism of ubiquitin-dependent regulation is the control of transcription factor stability by ubiquitin-mediated proteasomal degradation. Recent studies have suggested that ubiquitination may also regulate transcription factor activity by additional mechanisms. The myc transcription factor, for example, is rapidly turned over by ubiquitin-dependent proteolysis. The SCF-Skp2 ubiquitin E3 ligase promotes ubiquitination and degradation of myc (Kim et al. 2003; von der Lehr et al. 2003). Surprisingly, Skp2, the specificity subunit of the ubiquitin ligase, is also required for mycdependent activation of target genes. Thus, ubiquitination may regulate both activation and destruction of myc. Similarly, activation by a chimeric activator bearing the activation domain of the Herpes Simplex virus protein VP16 required the activity of an ubiquitin E3 ligase (Salghetti et al. 2001). In this case, direct fusion of ubiquitin to the activator bypassed the requirement for the ubiquitin ligase. This and other studies raise the possibility that ubiquitin may participate directly in protein interactions to promote transcription (Fig. 4).

Ubiquitin modification has also been suggested to have promoter-specific effects on transcription factor activity. The yeast transcription factor Met4 activates expression of genes required for methionine biosynthesis (MET genes) as well as several other groups of genes including those required for S-adenosylmethionine biosynthesis (SAM genes). In minimal media, addition of methionine leads to ubiquitination and degradation of Met4 and a corresponding reduction in MET gene expression (Rouillon et al. 2000). In rich media, Met4 is also ubiquitinated and MET gene expression reduced, even though the Met4 protein is stable under these conditions (Kaiser et al. 2000). Strikingly, under these conditions ubiquitin-modified Met4 is not recruited to the MET genes, but is recruited to the SAM genes (Kuras et al. 2002). Thus, ubiquitin modification regulates contextdependent activity of the Met4 transcription factor. In mammalian cells, monoubiquitination of the mammalian coactivator CTIIA has been suggested to increase assembly of CTIIA into a functional complex at the promoter (Greer et al. 2003). Posttranslational modification by ubiquitin or the ubiquitin-like protein SUMO may therefore regulate cooperative assembly of transcription factors at particular promoters by as yet to be determined mechanisms.

\section{SUMO and ubiquitin modify histones}

Posttranslational modification of histones by phosphorylation, acetylation, methylation, and ubiquitination regulates chromatin structure and dynamics (Jenuwein and Allis 2001). To add further complexity, histone H4 has recently been shown to be modified by SUMO (Shiio and Eisenman 2003). The site of SUMOylation in histone $\mathrm{H} 4$ has not been reported; however, the N-terminal tail was found to be a substrate for SUMO modification in vitro. As with other histone modifications, it is not clear if SUMOylation directly affects nucleosomal structure or packing or whether this modification serves to promote (or inhibit) interaction with nonhistone proteins, or both. Although the functional consequences of H4 SUMO modification on chromatin structure and gene expression are not yet understood, SUMO-modification of histones has been suggested to contribute to transcriptional repression. Targeting the SUMO E2 conjugating enzyme Ubc9 to DNA was found to increase levels of SUMO at the promoter (although not necessarily conjugated to histone $\mathrm{H} 4$ ) and repress transcription (Shiio and Eisenman 2003). Furthermore, covalent attachment of SUMO to histone $\mathrm{H} 4$ by gene fusion was found to increase association with HDAC1 and HP1, two transcriptional corepressors. Analysis of SUMO-dependent changes in chromatin structure will undoubtedly be complicated by the fact that many of the enzymes that regulate histone modifications, such as histone acetyltransferases and deacetylases, are themselves SUMO modified (Fig. 3).

Monoubiquitination of histone $\mathrm{H} 2 \mathrm{~B}$ in yeast regulates gene expression and telomeric silencing (Muratani and Tansey 2003). Studies of how ubiquitin modification of histones impacts chromatin structure and gene expression have provided two surprising mechanistic insights that may be relevant to understanding how conjugation of SUMO or ubiquitin regulates activity of many substrates. A major advance in understanding how monoubiquitination affects the nucleosome came with the demonstration by several groups that monoubiquitination of histone $\mathrm{H} 2 \mathrm{~B}$ in yeast is required for methylation 
of histone $\mathrm{H} 3$ at Lys 4 and Lys 79 (Briggs et al. 2002; Dover et al. 2002; Ng et al. 2002; Sun and Allis 2002). Although the mechanisms by which ubiquitination promotes methylation are incompletely understood, recruitment of proteasomal ATPases by ubiquitin-modified $\mathrm{H} 2 \mathrm{~B}$ has been implicated in this process (Ezhkova and Tansey 2004). Thus, these studies have shown that monoubiquitination of a protein can regulate the appearance of other posttranslational modifications in a tightly associated protein.

Another important lesson from recent studies of histone ubiquitination concerns the transitory nature of the modification. Mutation of the site of ubiquitination in $\mathrm{H} 2 \mathrm{~B}, \mathrm{~K} 123$, leads to decreased expression from the Gal1 and Gallo genes, suggesting that this modification contributes to full gene activation (Henry et al. 2003; Daniel et al. 2004). Consistent with this, ubiquitin-modified $\mathrm{H} 2 \mathrm{~B}$ is associated transiently with the GAL1 gene during induction (Daniel et al. 2004). Unexpectedly, the deubiquitinating enzyme Ubp8, which is a component of the SAGA coactivator complex, is also required for full induction of the Gall and Gallo genes (Henry et al. 2003; Daniel et al. 2004). These data suggest that, at some genes, addition and subsequent removal of ubiquitin from histone $\mathrm{H} 2 \mathrm{~B}$ are both required for full induction. Thus the reversible and transient nature of posttranslational modification by monoubiquitin is important for proper activity. A similar model of SUMO function has been proposed, in which sustained SUMO modification of a target is not required to achieve far-reaching consequences on protein activity (see below; Hardeland et al. 2002; Seeler and Dejean 2003).

\section{SUMO influences DNA repair}

Many factors and enzymes associated with DNA replication and repair including yeast PCNA, the helicase WRN, Topoisomerases I and II, and the thymine-DNA glycosylase enzyme TDG, are posttranslationally modified by SUMO (for review, see Muller et al. 2004). SUMO modification has been shown to regulate the subnuclear localization, protein-protein interactions, and activity of many factors involved in maintenance of the genome. Among these many examples, two are discussed here to illustrate how SUMO modification can regulate protein function. Studies of the yeast proliferating cell nuclear antigen (PCNA) highlight one strategy by which SUMO modification can impact protein function: competition with other modifications for a common lysine. Lys 164 in yeast PCNA is the major site of modification by both SUMO and ubiquitin; ubiquitination at this position is conserved in human PCNA although SUMO modification of human PCNA has not been described (Hoege et al. 2002; Kannouche et al. 2004). Modification of yeast PCNA at K164 by ubiquitin or SUMO has been suggested to direct PCNA for alternative functions (Table 1; Hoege et al. 2002; Stelter and Ulrich 2003; Haracska et al. 2004). Ubiquitination of PCNA is induced by DNA damage and monoubiquitinated PCNA is important for translesion synthesis repair whereas polyubiquinated
PCNA promotes error-free DNA repair (Hoege et al. 2002; Stelter and Ulrich 2003; Kannouche et al. 2004). Monoubiquitination of human PCNA has been shown to promote interactions with the translesion polymerase poln (Kannouche et al. 2004). Interestingly, this interaction involves both a PCNA-binding motif and a variant of the CUE ubiquitin-binding domain in poln. SUMOylation of yPCNA does more than prevent ubiquitin-dependent activities. SUMO modification of yPCNA has been suggested to increase activity of the translesion DNA polymerase and inhibit a recombination-dependent bypass mechanism during $S$ phase (Stelter and U1rich 2003; Haracska et al. 2004). Additional studies are required for a more detailed understanding of how SUMO modification alters PCNA interactions and activities.

Another mechanism by which SUMO modification can impact protein function is exemplified by the thymine-DNA glycosylase enzyme (TDG), which plays an important role in base excision repair in response to certain forms of DNA damage. TDG removes thymine and uracil from mismatched G-T and G-U base pairs. Human TDG does not readily dissociate from its product in vitro; release of TDG is necessary, however, to allow repair of the abasic site generated by TDG. Human TDG has recently been shown to be posttranslationally modified by SUMO and to bind noncovalently to SUMO (Hardeland et al. 2002). Strikingly, SUMO modification of TDG was found to alter its enzymatic properties. In particular, SUMO-modified TDG, although still possessing glycosylase activity, showed a reduced affinity for the DNA substrate. These and other observations support the hypothesis that the TDG reaction cycle is regulated by a SUMO-dependent conformational change (Fig. 5). According to this model, unmodified TDG binds and excises a mutant base, then DNA-bound TDG becomes SUMO modified. SUMO-modified TDG has a reduced affinity for the DNA product, possibly due to a conformational change dependent on an intramolecular interaction between a SUMO-binding domain in TDG and the conjugated SUMO. SUMO proteases would then restore the released TDG to its unmodified state. According to this model, sequential regulated cycles of SUMO addition and removal are required for optimal enzyme activity. Although it is too early to say whether dynamic cycles of SUMOylation and deSUMOylation are important for full activity of other SUMO-modified proteins, this model could account for the common observation that, for many substrates, only a small fraction is present in the SUMO modified form despite significant effects of SUMO modification on activity.

\section{Signaling to SUMO}

Similar to other well-characterized posttranslational modifications, SUMO conjugation to substrate proteins is regulated in response to external stimuli. One striking example of this is the significant increase in incorporation of SUMO-2/3 into higher molecular weight conjugates in response to heat shock or oxidative stress (Saitoh 
(1)

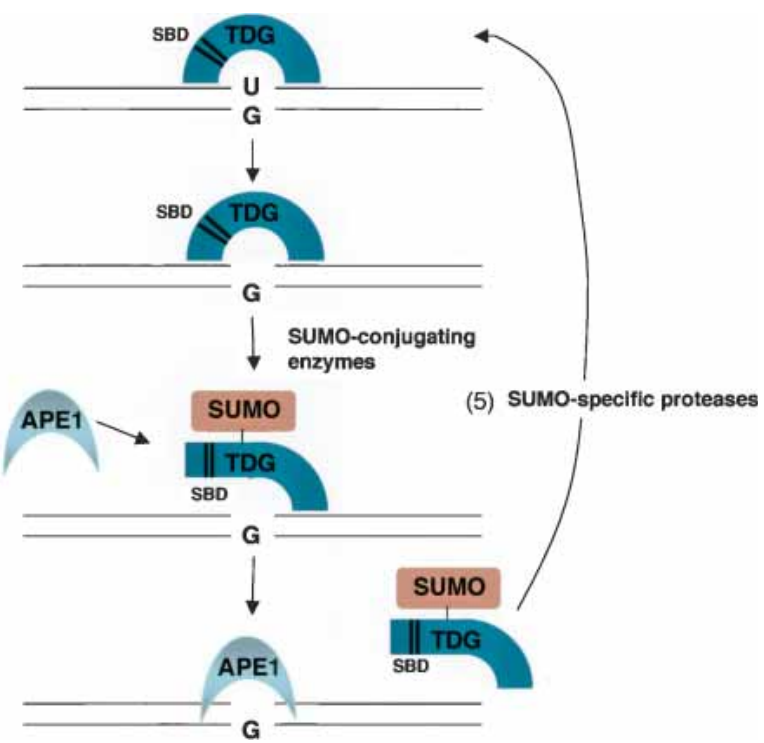

Figure 5. Dynamic cycles of SUMO conjugation and deconjugation may regulate DNA repair. In this model, the reaction cycle of the DNA-repair enzyme thymine-DNA glycosylase (TDG) is regulated by a SUMO-dependent conformational change (based on studies in Hardeland et al. 2002). Unmodified TDG is shown to bind a mutant base pair (1) and excise the appropriate base (2). (3) Product-bound TDG is then posttranslationally modified by SUMO, possibly stimulated by the next enzyme in the pathway, (AP)-endonuclease (APE1). SUMO modification is proposed to induce a conformational change in TDG possibly due to an intramolecular interaction between a SUMO-binding domain (SBD) in TDG and the conjugated SUMO. (4) SUMO-modified TDG has a reduced affinity for DNA and is released. APE1 and subsequent enzymes can then repair the DNA lesion. (5) Removal of SUMO by SUMO-specific proteases regenerates unmodified TDG so that the cycle can begin again. Dynamic SUMOylation/deSUMOylation may be important for regulated activity of many SUMO substrates. Adapted from Hardeland et al. (2002; (C) 2002 The EMBO Journal; http://www.nature.com/emboj).

and Hinchey 2000). Under conditions of prolonged hypoxia, SUMO modification of the transcription factor CREB was increased, correlating with an increase in SUMO-1 mRNA expression under these conditions (Comerford et al. 2003). SUMO modification of the IкB kinase regulator NEMO is induced by DNA damaging agents (Huang et al. 2003). In addition to the observed changes in SUMO modification in reponse to stress, SUMO modification of several substrates is regulated downstream of well-characterized signal transduction pathways and during the cell cycle (Everett et al. 1999; Hoege et al. 2002; Yang et al. 2003).

SUMOylation of several substrates is regulated by phosphorylation. Signal-dependent phosphorylation of the inhibitor of NFKB, IKB $\alpha$ inhibits SUMO modification in vitro even though this same modification stimulates ubiquitination (Desterro et al. 1998). Phosphorylation has been suggested to negatively regulate SUMO modification of PML and p53, whereas phosphorylation has been correlated with increased SUMOylation of HSF1 in response to heat shock (Muller et al. 1998, 2000; Hietakangas et al. 2003). Phosphorylation has been suggested to contribute to the regulation of PML SUMOylation during the cell cycle (Everett et al. 1999). Activation of the MAPK (mitogen-activated protein kinase) pathway was observed to reduce SUMOylation of the transcription factor Elk-1 (Yang et al. 2003). Because MAPK-dependent phosphorylation of Elk-1 stimulates activation whereas SUMO modification of Elk-1 is associated with repression, this finding suggests that the MAPK pathway coordinately derepresses and activates Elk-1. Of particular interest is the observation that several kinases, including dCamKII, DdMEK1, HIPK2, and FAK, are posttranslationally modified by SUMO and, in some cases, SUMO has been reported to regulate kinase localization and/or activity (Kim et al. 1999; Long and Griffith 2000; Sobko et al. 2002; Kadare et al. 2003). These examples suggest that cross-talk between the phosphorylation and SUMOylation pathways may be extensive and of fundamental importance in signal transduction.

Cross-talk between the sumoylation, ubiquitination, and acetylation pathways is also likely to be important for signal-dependent regulation of protein activity. Several proteins have been shown to be modified at a common lysine by ubiquitin, acetylation, or SUMO (Desterro et al. 1998; Braun et al. 2001; Hoege et al. 2002; Ross et al. 2002; Sapetschnig et al. 2002). In the cases documented to date, modification of a specific lysine by ubiquitin or SUMO has distinctly different, sometimes opposing, consequences (Table 1). Although competition for common lysines may be one aspect of regulation by SUMO and other modifiers, there are additional, and probably more important, mechanisms for cross-talk between these pathways. Acetylation has been suggested to enhance SUMOylation of histone H4 (Shiio and Eisenman 2003). Furthermore, several enzymes that add or remove acetyl groups (HATs and HDACs, respectively) are posttranslationally modified by SUMO, and SUMOylation has been reported to regulate localization and/or activity of some of these enzymes (David et al. 2002; Kirsh et al. 2002; Girdwood et al. 2003). SUMO modification of HDAC-1, for example, appears to stimulate deacetylase activity and transcriptional repression by this enzyme (Table 1; David et al. 2002; Cheng et al. 2004). SUMO has also been shown to modify the E3 ubiquitin ligase MDM2 and additional interactions between ubiquitin and SUMO pathway enzymes have been described (Buschmann et al. 2001; Hoege et al. 2002; Miyauchi et al. 2002; Xirodimas et al. 2002). The functional consequences of SUMOylation on ubiquitin pathway components is largely unknown. Furthermore, it is not known whether the activity of the proteins that mediate SUMO conjugation and deconjugation are themselves subject to regulation by posttranslational modification. Increased understanding of how posttranslational modification by SUMO is integrated into the complex web of signaling pathways involving other posttranslational modifications may yield surprises about wellknown signaling pathways. 


\section{SUMO and disease}

As discussed here, although posttranslational modification by ubiquitin and SUMO generally have very different effects on substrate proteins, the pathways that add and remove SUMO, as well as the mechanisms by which SUMO conjugation regulates localization and activity of substrate proteins, share many similarities with ubiquitin. The finding that SUMO substrates include many proteins with important roles in regulating cell proliferation and differentiation suggests that, like ubiquitination, altered SUMOylation may contribute to disease onset or progression. In fact, recent data suggest that several diseases including pathogenic infection, cancer, and neurodegenerative disorders are associated with alterations in SUMOylation. The cellular SUMOylation system is exploited by several viral and bacterial pathogens to favor replication and infection (Wilson and Rangasamy 2001). One striking example is the finding that the YopJ protein of Yersinia pestis, the bacterial agent for the Black Plague, encodes a SUMO protease homolog whose activity contributes to inhibition of the host immune response (Orth et al. 2000). The observation that the activity and/or localization of several tumor supressors and oncogenes is regulated by SUMO modification raises the possibility that alterations in the SUMO conjugation machinery or alterations in SUMO modification of specific substrates may contribute to cancer. Although this hypothesis requires further investigation, it is interesting to note that in acute promyelocytic leukemia, the PML-RAR $\alpha$ fusion protein is not SUMO modified whereas arsenic trioxide, an effective treatment for this disorder, restores SUMOylation of the fusion protein (Muller et al. 1998). SUMO has been shown to localize to intranuclear inclusions that characterize several neurodegenerative diseases (Terashima et al. 2002; Ueda et al. 2002; Pountney et al. 2003). Overexpression of SUMO-2 influences processing of the $\beta$-amyloid precursor protein, an event implicated in the onset of Alzheimer's disease, and genetic manipulation of the SUMO conjugation pathway in Drosophila indicates that SUMOylation contributes to neurodegeneration in at least two polyglutamine repeat diseases, spinal and bulbar muscular atrophy (SBMA) and Huntington's (Chan et al. 2002; Li et al. 2003; Steffan et al. 2004). Thus, in addition to the possibility of revealing new insights into the mechanisms that regulate gene expression, genome maintenance, and signal transduction, an increased understanding of the regulation and function of the posttranslational modifier SUMO may provide new targets for therapeutic intervention in several human diseases.

\section{Acknowledgments}

I thank Yan Xuan for help with the figures. I also thank Bill Tansey, Alex Gann, Wade Harper, Michael Carey, Karl Munger, and members of my laboratory for helpful discussions and critical reading of the manuscript.

\section{References}

Abdel-Hafiz, H., Takimoto, G.S., Tung, L., and Horwitz, K.B. 2002. The inhibitory function in human progesterone receptor $\mathrm{N}$ termini binds SUMO-1 protein to regulate autoinhibition and transrepression. J. Biol. Chem. 277: 33950-33956.

Ahn, J.H., Xu, Y., Jang, W.J., Matunis, M.J., and Hayward, G.S. 2001. Evaluation of interactions of human cytomegalovirus immediate-early IE2 regulatory protein with small ubiquitin-like modifiers and their conjugation enzyme Ubc9. J. Virol. 75: 3859-3872.

Azuma, Y., Arnaoutov, A., and Dasso, M. 2003. SUMO-2/3 regulates topoisomerase II in mitosis. J. Cell Biol. 163: $477-$ 487.

Bailey, D. and O'Hare, P. 2002. Herpes simplex virus 1 ICP0 co-localizes with a SUMO-specific protease. J. Gen. Virol. 83: 2951-2964.

Bayer, P., Arndt, A., Metzger, S., Mahajan, R., Melchior, F., Jaenicke, R., and Becker, J. 1998. Structure determination of the small ubiquitin-related modifier SUMO-1. I. Mol. Biol. 280: $275-286$.

Bernier-Villamor, V., Sampson, D.A., Matunis, M.J., and Lima, C.D. 2002. Structural basis for E2-mediated SUMO conjugation revealed by a complex between ubiquitin-conjugating enzyme Ubc9 and RanGAP1. Cell 108: 345-356.

Best, J.L., Ganiatsas, S., Agarwal, S., Changou, A., Salomoni, P., Shirihai, O., Meluh, P.B., Pandolfi, P.P., and Zon, L.I. 2002. SUMO-1 Protease-1 (SuPr-1) regulates gene transcription through PML. Mol. Cell 10: 843-855.

Bies, J., Markus, J., and Wolff, L. 2002. Covalent attachment of SUMO-1 protein to the negative regulatory domain of the c-Myb transcription factor modifies its stability and transactivation capacity. J. Biol. Chem. 277: 8999-9009.

Bohren, K.M., Nadkarni, V., Song, J.H., Gabbay, K.H., and Owerbach, D. 2004. A M55V polymorphism in a novel SUMO gene (SUMO-4) differentially activates heat shock transcription factors and is associated with susceptibility to type I diabetes mellitus. J. Biol. Chem. 279: 27233-27238.

Braun, H., Koop, R., Ertmer, A., Nacht, S., and Suske, G. 2001. Transcription factor Sp3 is regulated by acetylation. Nucleic Acids Res. 29: 4994-5000.

Briggs, S.D., Xiao, T., Sun, Z.W., Caldwell, J.A., Shabanowitz, J., Hunt, D.F., Allis, C.D., and Strahl, B.D. 2002. Gene silencing: Trans-histone regulatory pathway in chromatin. Nature 418: 498.

Buschmann, T., Lerner, D., Lee, C.G., and Ronai, Z. 2001. The Mdm-2 amino terminus is required for $\mathrm{Mdm} 2$ binding and SUMO-1 conjugation by the E2 SUMO-1 conjugating enzyme Ubc9. J. Biol. Chem. 276: 40389-40395.

Bylebyl, G.R., Belichenko, I., and Johnson, E.S. 2003. The SUMO isopeptidase Ulp2 prevents accumulation of SUMO chains in yeast. J. Biol. Chem. 278: 44113-44120.

Chan, H.Y., Warrick, J.M., Andriola, I., Merry, D., and Bonini, N.M. 2002. Genetic modulation of polyglutamine toxicity by protein conjugation pathways in Drosophila. Hum. Mol. Genet. 11: 2895-2904.

Cheng, J., Wang, D., Wang, Z., and Yeh, E.T. 2004. SENP1 enhances androgen receptor-dependent transcription through desumoylation of histone deacetylase 1. Mol. Cell Biol. 24: 6021-6028.

Chung, C.D., Liao, J., Liu, B., Rao, X., Jay, P., Berta, P., and Shuai, K. 1997. Specific inhibition of Stat3 signal transduction by PIAS3. Science 278: 1803-1805.

Comerford, K.M., Leonard, M.O., Karhausen, J., Carey, R., Colgan, S.P., and Taylor, C.T. 2003. Small ubiquitin-related modifier-1 modification mediates resolution of CREB-de- 
pendent responses to hypoxia. Proc. Natl. Acad. Sci. 100: 986-991.

Conaway, R.C., Brower, C.S., and Conaway, J.W. 2002. Emerging roles of ubiquitin in transcription regulation. Science 296: $1254-1258$.

Daniel, J.A., Torok, M.S., Sun, Z.W., Schieltz, D., Allis, C.D., Yates III, J.R., and Grant, P.A. 2004. Deubiquitination of histone $\mathrm{H} 2 \mathrm{~B}$ by a yeast acetyltransferase complex regulates transcription. J. Biol. Chem. 279: 1867-1871.

David, G., Neptune, M.A., and DePinho, R.A. 2002. SUMO-1 modification of histone deacetylase 1 (HDAC1) modulates its biological activities. J. Biol. Chem. 277: 23658-23663.

Desterro, J.M., Rodriguez, M.S., and Hay, R.T. 1998. SUMO-1 modification of ІкB $\alpha$ inhibits NF-кB activation. Mol. Cell 2: 233-239.

Dobreva, G., Dambacher, J., and Grosschedl, R. 2003. SUMO modification of a novel MAR-binding protein, SATB2, modulates immunoglobulin $\mu$ gene expression. Genes \& Dev. 17: 3048-3061.

Dover, J., Schneider, J., Tawiah-Boateng, M.A., Wood, A., Dean, K., Johnston, M., and Shilatifard, A. 2002. Methylation of histone $\mathrm{H} 3$ by COMPASS requires ubiquitination of histone H2B by Rad6. J. Biol. Chem. 277: 28368-28371.

Engelhardt, O.G., Boutell, C., Orr, A., Ullrich, E., Haller, O., and Everett, R.D. 2003. The homeodomain-interacting kinase PKM (HIPK-2) modifies ND10 through both its kinase domain and a SUMO-1 interaction motif and alters the posttranslational modification of PML. Exp. Cell Res. 283: 36-50.

Everett, R.D., Lomonte, P., Sternsdorf, T., van Driel, R., and Orr, A. 1999. Cell cycle regulation of PML modification and ND10 composition. J. Cell Sci. 112: 4581-4588.

Ezhkova, E. and Tansey, W.P. 2004. Proteasomal ATPases link ubiquitylation of histone $\mathrm{H} 2 \mathrm{~B}$ to methylation of histone $\mathrm{H} 3$. Mol. Cell 13: 435-442.

Garcia-Higuera, I., Taniguchi, T., Ganesan, S., Meyn, M.S., Timmers, C., Hejna, J., Grompe, M., and D'Andrea, A.D. 2001. Interaction of the Fanconi anemia proteins and BRCA1 in a common pathway. Mol. Cell 7: 249-262.

Gill, G. 2003. Post-translational modification by the small ubiquitin-related modifier SUMO has big effects on transcription factor activity. Curr. Opin. Genet. Dev. 13: 108-113.

Girdwood, D., Bumpass, D., Vaughan, O.A., Thain, A., Anderson, L.A., Snowden, A.W., Garcia-Wilson, E., Perkins, N.D., and Hay, R.T. 2003. P300 transcriptional repression is mediated by SUMO modification. Mol. Cell 11: 1043-1054.

Gong, L., Millas, S., Maul, G.G., and Yeh, E.T. 2000. Differential regulation of sentrinized proteins by a novel sentrin-specific protease. J. Biol. Chem. 275: 3355-3359.

Goodson, M.L., Hong, Y., Rogers, R., Matunis, M.J., Park-Sarge, O.K., and Sarge, K.D. 2001. Sumo-1 modification regulates the DNA binding activity of heat shock transcription factor 2, a promyelocytic leukemia nuclear body associated transcription factor. J. Biol. Chem. 276: 18513-18518.

Greer, S.F., Zika, E., Conti, B., Zhu, X.S., and Ting, J.P. 2003. Enhancement of CIITA transcriptional function by ubiquitin. Nat. Immunol. 4: 1074-1082.

Gross, M., Liu, B., Tan, J., French, F.S., Carey, M., and Shuai, K. 2001. Distinct effects of PIAS proteins on androgen-mediated gene activation in prostate cancer cells. Oncogene 20: 3880-3887.

Gross, M., Yang, R., Top, I., Gasper, C., and Shuai, K. 2004. PIASy-mediated repression of the androgen receptor is independent of sumoylation. Oncogene 23: 3059-3066.

Hang, J. and Dasso, M. 2002. Association of the human SUMO-1 protease SENP2 with the nuclear pore. J. Biol. Chem. 277: 19961-19966.
Haracska, L., Torres-Ramos, C.A., Johnson, R.E., Prakash, S., and Prakash, L. 2004. Opposing effects of ubiquitin conjugation and SUMO modification of PCNA on replicational bypass of DNA lesions in Saccharomyces cerevisiae. Mol. Cell Biol. 24: 4267-4274.

Hardeland, U., Steinacher, R., Jiricny, J., and Schar, P. 2002. Modification of the human thymine-DNA glycosylase by ubiquitin-like proteins facilitates enzymatic turnover. EMBO I. 21: 1456-1464.

Henry, K.W., Wyce, A., Lo, W.S., Duggan, L.J., Emre, N.C., Kao, C.F., Pillus, L., Shilatifard, A., Osley, M.A., and Berger, S.L. 2003. Transcriptional activation via sequential histone H2B ubiquitylation and deubiquitylation, mediated by SAGA-associated Ubp8. Genes \& Dev. 17: 2648-2663.

Hietakangas, V., Ahlskog, J.K., Jakobsson, A.M., Hellesuo, M., Sahlberg, N.M., Holmberg, C.I., Mikhailov, A., Palvimo, J.J., Pirkkala, L., and Sistonen, L. 2003. Phosphorylation of serine 303 is a prerequisite for the stress-inducible SUMO modification of heat shock factor 1. Mol. Cell Biol. 23: 2953-2968.

Hoege, C., Pfander, B., Moldovan, G.L., Pyrowolakis, G., and Jentsch, S. 2002. RAD6-dependent DNA repair is linked to modification of PCNA by ubiquitin and SUMO. Nature 419: 135-141.

Holmstrom, S., Van Antwerp, M.E., and Iniguez-Lluhi, J.A. 2003. Direct and distinguishable inhibitory roles for SUMO isoforms in the control of transcriptional synergy. Proc. Natl. Acad. Sci. 100: 15758-15763.

Hong, Y., Rogers, R., Matunis, M.J., Mayhew, C.N., Goodson, M.L., Park-Sarge, O.K., Sarge, K.D., and Goodson, M. 2001. Regulation of heat shock transcription factor 1 by stressinduced SUMO-1 modification. J. Biol. Chem. 276: 4026340267.

Huang, T.T., Wuerzberger-Davis, S.M., Wu, Z.H., and Miyamoto, S. 2003. Sequential modification of NEMO/IKK $\gamma$ by SUMO-1 and ubiquitin mediates NF-кB activation by genotoxic stress. Cell 115: 565-576.

Iniguez-Lluhi, J.A. and Pearce, D. 2000. A common motif within the negative regulatory regions of multiple factors inhibits their transcriptional synergy. Mol. Cell Biol. 20: 6040-6050.

Jackson, P.K. 2001. A new RING for SUMO: Wrestling transcriptional responses into nuclear bodies with PIAS family E3 SUMO ligases. Genes \& Dev. 15: 3053-3058.

Jenuwein, T. and Allis, C.D. 2001. Translating the histone code. Science 293: 1074-1080.

Johnson, E.S. and Gupta, A.A. 2001. An E3-like factor that promotes SUMO conjugation to the yeast septins. Cell 106: $735-744$.

Kadare, G., Toutant, M., Formstecher, E., Corvol, J.C., Carnaud, M., Boutterin, M.C., and Girault, J.A. 2003. PIAS1-mediated sumoylation of focal adhesion kinase activates its autophosphorylation. J. Biol. Chem. 278: 47434-47440.

Kagey, M.H., Melhuish, T.A., and Wotton, D. 2003. The polycomb protein Pc2 is a SUMO E3. Cell 113: 127-137.

Kahyo, T., Nishida, T., and Yasuda, H. 2001. Involvement of PIAS1 in the sumoylation of tumor suppressor p53. Mol. Cell 8: 713-718.

Kaiser, P., Flick, K., Wittenberg, C., and Reed, S.I. 2000. Regulation of transcription by ubiquitination without proteolysis: Cdc34/SCF(Met30)-mediated inactivation of the transcription factor Met4. Cell 102: 303-314.

Kannouche, P.L., Wing, J., and Lehmann, A.R. 2004. Interaction of Human DNA polymerase $\eta$ with monoubiquitinated PCNA; A possible mechanism for the polymerase switch in response to DNA damage. Mol. Cell 14: 491-500.

Kim, Y.H., Choi, C.Y., and Kim, Y. 1999. Covalent modification of the homeodomain-interacting protein kinase 2 (HIPK2) by 
the ubiquitin-like protein SUMO-1. Proc. Nat1. Acad. Sci. 96: $12350-12355$.

Kim, K.I., Baek, S.H., Jeon, Y.J., Nishimori, S., Suzuki, T., Uchida, S., Shimbara, N., Saitoh, H., Tanaka, K., and Chung, C.H. 2000. A new SUMO-1-specific protease, SUSP1, that is highly expressed in reproductive organs. J. Biol. Chem. 275: 14102-14106.

Kim, J., Cantwell, C.A., Johnson, P.F., Pfarr, C.M., and Williams, S.C. 2002. Transcriptional activity of CCAAT/enhancer-binding proteins is controlled by a conserved inhibitory domain that is a target for sumoylation. J. Biol. Chem. 277: 38037-38044.

Kim, K.I., Baek, S.H., and Chung, C.H. 2002. Versatile protein tag, SUMO: Its enzymology and biological function. J. Cell Physiol. 191: 257-268.

Kim, S.Y., Herbst, A., Tworkowski, K.A., Salghetti, S.E., and Tansey, W.P. 2003. Skp2 regulates Myc protein stability and activity. Mol. Cell 11: 1177-1188.

Kirsh, O., Seeler, J.S., Pichler, A., Gast, A., Muller, S., Miska, E., Mathieu, M., Harel-Bellan, A., Kouzarides, T., Melchior, F., et al. 2002. The SUMO E3 ligase RanBP2 promotes modification of the HDAC4 deacetylase. EMBO J. 21: 2682-2691.

Kotaja, N., Aittomaki, S., Silvennoinen, O., Palvimo, J.J., and Janne, O.A. 2000. ARIP3 (androgen receptor-interacting protein 3) and other PIAS (protein inhibitor of activated STAT) proteins differ in their ability to modulate steroid receptordependent transcriptional activation. Mol. Endocrinol. 14: 1986-2000.

Kotaja, N., Karvonen, U., Janne, O.A., and Palvimo, J.J. 2002. PIAS proteins modulate transcription factors by functioning as SUMO-1 ligases. Mol. Cell Biol. 22: 5222-5234.

Kuras, L., Rouillon, A., Lee, T., Barbey, R., Tyers, M., and Thomas, D. 2002. Dual regulation of the met4 transcription factor by ubiquitin-dependent degradation and inhibition of promoter recruitment. Mol. Cell 10: 69-80.

Le Drean, Y., Mincheneau, N., Le Goff, P., and Michel, D. 2002. Potentiation of glucocorticoid receptor transcriptional activity by sumoylation. Endocrinology 143: 3482-3489.

Lehembre, F., Badenhorst, P., Muller, S., Travers, A., Schweisguth, F., and Dejean, A. 2000. Covalent modification of the transcriptional repressor tramtrack by the ubiquitin-related protein Smt3 in Drosophila flies. Mol. Cell Biol. 20: 10721082.

Li, S.J. and Hochstrasser, M. 1999. A new protease required for cell-cycle progression in yeast. Nature 398: 246-251.

. 2003. The Ulp1 SUMO isopeptidase: Distinct domains required for viability, nuclear envelope localization, and substrate specificity. J. Cell Biol. 160: 1069-1081.

Li, Y., Wang, H., Wang, S., Quon, D., Liu, Y.W., and Cordell, B. 2003. Positive and negative regulation of APP amyloidogenesis by sumoylation. Proc. Natl. Acad. Sci. 100: 259-264.

Lin, J., Johannsen, E., Robertson, E., and Kieff, E. 2002. EpsteinBarr virus nuclear antigen $3 \mathrm{C}$ putative repression domain mediates coactivation of the LMP1 promoter with EBNA-2. J. Virol. 76: 232-242.

Liu, B., Liao, J., Rao, X., Kushner, S.A., Chung, C.D., Chang, D.D., and Shuai, K. 1998. Inhibition of Stat1-mediated gene activation by PIAS1. Proc. Nat1. Acad. Sci. 95: 10626-10631.

Long, X. and Griffith, L.C. 2000. Identification and characterization of a SUMO-1 conjugation system that modifies neuronal calcium/calmodulin-dependent protein kinase II in Drosophila melanogaster. J. Biol. Chem. 275: 40765-40776.

Mahajan, R., Delphin, C., Guan, T., Gerace, L., and Melchior, F. 1997. A small ubiquitin-related polypeptide involved in targeting RanGAP1 to nuclear pore complex protein RanBP2. Cell 88: 97-107.
Matunis, M.J., Coutavas, E., and Blobel, G. 1996. A novel ubiquitin-like modification modulates the partitioning of the Ran-GTPase-activating protein RanGAP1 between the cytosol and the nuclear pore complex. J. Cell Biol. 135: 14571470.

Matunis, M.J., Wu, J., and Blobel, G. 1998. SUMO-1 modification and its role in targeting the Ran GTPase-activating protein, RanGAP1, to the nuclear pore complex. I. Cell Biol. 140: 499-509.

Megidish, T., Xu, J.H. and Xu, C.W. 2002. Activation of p53 by protein inhibitor of activated Stat1 (PIAS1). J. Biol. Chem. 277: 8255-8259.

Melchior, F., Schergaut, M., and Pichler, A. 2003. SUMO: Ligases, isopeptidases and nuclear pores. Trends Biochem. Sci. 28: 612-618.

Minty, A., Dumont, X., Kaghad, M., and Caput, D. 2000. Covalent modification of p73alpha by SUMO-1. Two-hybrid screening with p73 identifies novel SUMO-1-interacting proteins and a SUMO-1 interaction motif. I. Biol. Chem. 275: 36316-36323.

Miyauchi, Y., Yogosawa, S., Honda, R., Nishida, T., and Yasuda, H. 2002. Sumoylation of Mdm2 by protein inhibitor of activated STAT (PIAS) and RanBP2 enzymes. J. Biol. Chem. 277: 50131-50136.

Muller, S., Matunis, M.J., and Dejean, A. 1998. Conjugation with the ubiquitin-related modifier SUMO-1 regulates the partitioning of PML within the nucleus. EMBO J. 17: 61-70.

Muller, S., Berger, M., Lehembre, F., Seeler, J.S., Haupt, Y., and Dejean, A. 2000. c-Jun and p53 activity is modulated by SUMO-1 modification. J. Biol. Chem. 275: 13321-13329.

Muller, S., Ledl, A., and Schmidt, D. 2004. SUMO: A regulator of gene expression and genome integrity. Oncogene 23: 1998-2008.

Muratani, M. and Tansey, W.P. 2003. How the ubiquitin-proteasome system controls transcription. Nat. Rev. Mol. Cell Biol. 4: 192-201.

Ng, H.H., Xu, R.M., Zhang, Y.m., and Struhlm, K. 2002. Ubiquitination of histone $\mathrm{H} 2 \mathrm{~B}$ by Rad6 is required for efficient Dot1-mediated methylation of histone H3 lysine 79. J. Biol. Chem. 277: 34655-34657.

Nishida, T., Tanaka, H., and Yasuda, H. 2000. A novel mammalian Smt3-specific isopeptidase 1 (SMT3IP1) localized in the nucleolus at interphase. Eur. J. Biochem. 267: 64236427.

Nishida, T., Kaneko, F., Kitagawa, M., and Yasuda, H. 2001. Characterization of a novel mammalian SUMO-1/Smt3-specific isopeptidase, a homologue of rat axam, which is an axin-binding protein promoting $\beta$-catenin degradation. $J$. Biol. Chem. 276: 39060-39066.

Orth, K., Xu, Z., Mudgett, M.B., Bao, Z.Q., Palmer, L.E., Bliska, J.B., Mangel, W.F., Staskawicz, B., and Dixon, J.E. 2000. Disruption of signaling by Yersinia effector YopJ, a ubiquitinlike protein protease. Science 290: 1594-1597.

Pichler, A., Gast, A., Seeler, J.S., Dejean, A., and Melchior, F. 2002. The nucleoporin RanBP2 has SUMO1 E3 ligase activity. Cell 108: 109-120.

Pickart, C.M. 2001. Mechanisms underlying ubiquitination. Annu. Rev. Biochem. 70: 503-533.

Poukka, H., Karvonen, U., Janne, O.A., and Palvimo, J.J. 2000. Covalent modification of the androgen receptor by small ubiquitin-like modifier 1 (SUMO-1). Proc. Nat1. Acad. Sci. 97: 14145-14150.

Pountney, D.L., Huang, Y., Burns, R.J., Haan, E., Thompson, P.D., Blumbergs, P.C., and Gai, W.P. 2003. SUMO-1 marks the nuclear inclusions in familial neuronal intranuclear inclusion disease. Exp. Neurol. 184: 436-446. 
Rodriguez, M.S., Dargemont, C., and Hay, R.T. 2001. SUMO-1 conjugation in vivo requires both a consensus modification motif and nuclear targeting. J. Biol. Chem. 276: 1265412659.

Rosendorff, A., Illanes, D., David, G., Lin, J., Kieff, E., and Johannsen, E. 2004. EBNA3C coactivation with EBNA2 requires a SUMO homology domain. J. Virol. 78: 367-377.

Ross, S., Best, J.L., Zon, L.I., and Gill, G. 2002. SUMO-1 modification represses $S p 3$ transcriptional activation and modulates its subnuclear localization. Mol. Cell 10: 831-842.

Rouillon, A., Barbey, R., Patton, E.E., Tyers, M., and Thomas, D. 2000. Feedback-regulated degradation of the transcriptional activator Met4 is triggered by the SCF(Met30) complex. EMBO J. 19: 282-294.

Sachdev, S., Bruhn, L., Sieber, H., Pichler, A., Melchior, F., and Grosschedl, R. 2001. PIASy, a nuclear matrix-associated SUMO E3 ligase, represses LEF1 activity by sequestration into nuclear bodies. Genes \& Dev. 15: 3088-3103.

Saitoh, H. and Hinchey, J. 2000. Functional heterogeneity of small ubiquitin-related protein modifiers SUMO-1 versus SUMO-2/3. J. Biol. Chem. 275: 6252-6258.

Salghetti, S.E., Caudy, A.A., Chenoweth, J.G., and Tansey, W.P. 2001. Regulation of transcriptional activation domain function by ubiquitin. Science 293: 1651-1653.

Sapetschnig, A., Rischitor, G., Braun, H., Doll, A., Schergaut, M., Melchior, F., and Suske, G. 2002. Transcription factor $\mathrm{Sp} 3$ is silenced through SUMO modification by PIAS1. EMBO T. 21: 5206-5215.

Schnell, J.D. and Hicke, L. 2003. Non-traditional functions of ubiquitin and ubiquitin-binding proteins. J. Biol. Chem. 278: $35857-35860$.

Seeler, J.S. and Dejean, A. 2003. Nuclear and unclear functions of SUMO. Nat. Rev. Mol. Cell Biol. 4: 690-699.

Shiio, Y. and Eisenman, R.N. 2003. Histone sumoylation is associated with transcriptional repression. Proc. Natl. Acad. Sci. 100: 13225-13230.

Sloper-Mould, K., Jemc, J., Pickart, C., and Hicke, L. 2001. Distinct functional surface regions on ubiquitin. J. Biol. Chem. 276: 30483-30489.

Sobko, A., Ma, H., and Firtel, R.A. 2002. Regulated SUMOylation and ubiquitination of DdMEK1 is required for proper chemotaxis. Dev. Cell 2: 745-756.

Stade, K., Vogel, F., Schwienhorst, I., Meusser, B., Volkwein, C., Nentwig, B., Dohmen, R.J., and Sommer, T. 2002. A lack of SUMO conjugation affects cNLS-dependent nuclear protein import in yeast. J. Biol. Chem. 277: 49554-49561.

Steffan, J.S., Agrawal, N., Pallos, J., Rockabrand, E., Trotman, L.C., Slepko, N., Illes, K., Lukacsovich, T., Zhu, Y.Z., Cattaneo, E., et al. 2004. SUMO modification of Huntingtin and Huntington's disease pathology. Science 304: 100-104.

Stelter, P. and Ulrich, H.D. 2003. Control of spontaneous and damage-induced mutagenesis by SUMO and ubiquitin conjugation. Nature 425: 188-191.

Sternsdorf, T., Jensen, K., Reich, B., and Will, H. 1999. The nuclear dot protein sp100, characterization of domains necessary for dimerization, subcellular localization, and modification by small ubiquitin-like modifiers. J. Biol. Chem. 274: $12555-12566$.

Subramanian, L., Benson, M.D., and Iniguez-Lluhi, J.A. 2003. A synergy control motif within the attenuator domain of CCAAT/enhancer-binding protein alpha inhibits transcriptional synergy through its PIASy-enhanced modification by SUMO-1 or SUMO-3. J. Biol. Chem. 278: 9134-9141.

Sun, Z.W. and Allis, C.D. 2002. Ubiquitination of histone H2B regulates $\mathrm{H} 3$ methylation and gene silencing in yeast. $\mathrm{Na}$ ture 418: 104-108.
Takahashi, Y., Kahyo, T., Toh, E.A., Yasuda, H., and Kikuchi, Y. 2001. Yeast Ull1/Siz1 is a novel SUMO1/Smt3 ligase for septin components and functions as an adaptor between conjugating enzyme and substrates. J. Biol. Chem. 276: 4897348977.

Tatham, M.H., Jaffray, E., Vaughan, O.A., Desterro, J.M., Botting, C.H., Naismith, J.H., and Hay, R.T. 2001. Polymeric chains of SUMO-2 and SUMO-3 are conjugated to protein substrates by SAE1/SAE2 and Ubc9. J. Biol. Chem. 276: $35368-35374$.

Taylor, D.L., Ho, J.C., Oliver, A., and Watts, F.Z. 2002. Cellcycle-dependent localisation of Ulp1, a Schizosaccharomyces pombe Pmt3 (SUMO)-specific protease. I. Cell Sci. 115: $1113-1122$.

Terashima, T., Kawai, H., Fujitani, M., Maeda, K., and Yasuda, H. 2002. SUMO-1 co-localized with mutant atrophin-1 with expanded polyglutamines accelerates intranuclear aggregation and cell death. NeuroReport 13: 2359-2364.

Tian, S., Poukka, H., Palvimo, J.J., and Janne, O.A. 2002. Small ubiquitin-related modifier-1 (SUMO-1) modification of the glucocorticoid receptor. Biochem. J. 367: 907-911.

Ueda, H., Goto, J., Hashida, H., Lin, X., Oyanagi, K., Kawano, H., Zoghbi, H.Y., Kanazawa, I., and Okazawa, H. 2002. Enhanced SUMOylation in polyglutamine diseases. Biochem. Biophys. Res. Commun. 293: 307-313.

Verger, A., Perdomo, J.. and Crossley, M. 2003. Modification with SUMO. A role in transcriptional regulation. $E M B O$ Rep. 4: 137-142.

Vertegaal, A.C., Ogg, S.C., Jaffray, E., Rodriguez, M.S., Hay, R.T., Andersen, J.S., Mann, M., and Lamond, A.I. 2004. A proteomic study of SUMO-2 target proteins. J. Biol. Chem. (in press).

von der Lehr, N., Johansson, S., and Larsson, L.G. 2003. Implication of the ubiquitin/proteasome system in Myc-regulated transcription. Cell Cycle 2: 403-407.

Wilson, V.G. and Rangasamy, D. 2001. Viral interaction with the host cell sumoylation system. Virus Res. 81: 17-27.

Xirodimas, D.P., Chisholm, J., Desterro, J.M., Lane, D.P., and Hay, R.T. 2002. P14ARF promotes accumulation of SUMO-1 conjugated (H)Mdm2. FEBS Lett. 528: 207-211.

Yang, S.H. and Sharrocks, A.D. 2004. SUMO promotes HDACmediated transcriptional repression. Mol. Cell 13: 611-617.

Yang, S.H., Jaffray, E., Hay, R.T., and Sharrocks, A.D. 2003. Dynamic interplay of the SUMO and ERK pathways in regulating Elk-1 transcriptional activity. Mol. Cell 12: 63-74.

Zhao, Y., Kwon, S.W., Anselmo, A., Kaur, K., and White, M.A. 2004. Broad-spectrum identification of cellular SUMO substrate proteins. J. Biol. Chem. 279: 20999-21002.

Zhong, S., Muller, S., Ronchetti, S., Freemont, P.S., Dejean, A., and Pandolfi, P.P. 2000a. Role of SUMO-1-modified PML in nuclear body formation. Blood 95: 2748-2752.

Zhong, S., Salomoni, P., and Pandolfi, P.P. 2000b. The transcriptional role of PML and the nuclear body. Nat. Cell Biol. 2: E85-E90. 


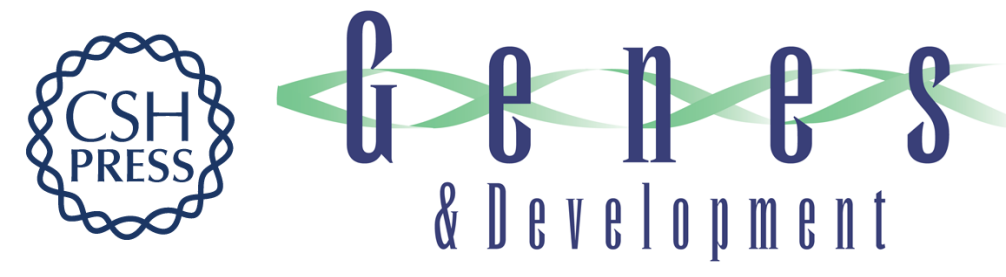

\section{SUMO and ubiquitin in the nucleus: different functions, similar mechanisms?}

\section{Grace Gill}

Genes Dev. 2004, 18:

Access the most recent version at doi:10.1101/gad.1214604

$\begin{array}{ll}\text { References } & \begin{array}{l}\text { This article cites } 122 \text { articles, } 70 \text { of which can be accessed free at: } \\ \text { http://genesdev.cshlp.org/content/18/17/2046.full.html\#ref-list-1 }\end{array}\end{array}$

License

Email Alerting Receive free email alerts when new articles cite this article - sign up in the box at the top Service right corner of the article or click here.

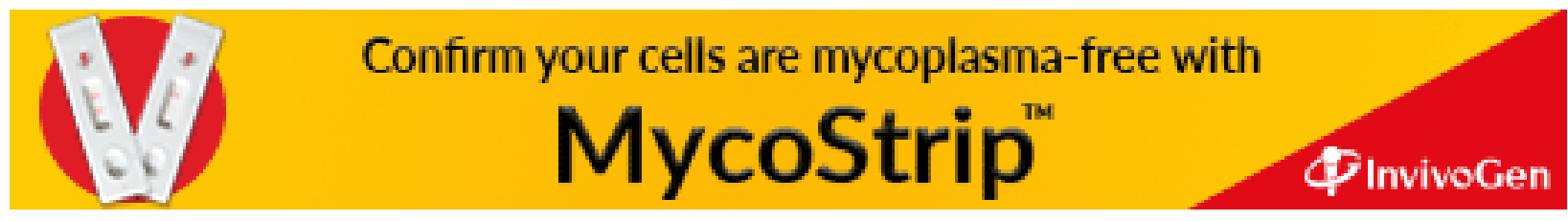

